\title{
Hepcidin interplay in regulating iron level at liver, intestine and reticoendothelial system
}

\begin{abstract}
Iron homeostasis is an interplay of numerous proteins which helps in regulating various pathways of iron recycling, absorption and excretion. Hepcidin is an important protein which plays a crucial role in regulating iron metabolism through its iron sensing and signaling pathway. Ferroportin normally transports iron in the circulation in case of need transcription of hepcidin in cases of excess iron negatively regulates the ferroportin activity by causing destruction of it. Nevertheless, hepcidin level increases in various physiological and pathological conditions as inflammation, chronic infection, hemochromatosis etc. Thus further knowledge of this pathway will help in better understanding of iron homeostasis in various conditions and help in development of therapeutic drugs.
\end{abstract}

Keywords: hepcidin, ferroportin, hemoglobin, ceruloplasmin, transferring
Volume 3 Issue I - 2017

\author{
Jayant Kumar,' Isabella reccia,' Tomokazu \\ Kusano,' Swati Agrawal' \\ 'Department of Hepato-Pancreato-Biliary Surgery (HPB), \\ Imperial College, London, UK \\ ${ }^{2}$ John Radcliff Hospital, University of Oxford, UK
}

\begin{abstract}
Correspondence: Jayant Kumar, MD, MS. Department of Surgery \& Cancer, Imperial College London, London, WI20HS, UK.Email jkumar@ic.ac.uk
\end{abstract}

Received: December 0I, 2016 | Published: January 23, 2017
Abbreviations: IRP1, iron regulatory protein 1; IRP2, iron regulatory protein 2; DMT1, divalent metal transporter 1; BMP6, bone morphogenic protein 6 ; LEAP, liver expressed antimicrobial peptide; HAMP, hepcidin antimicrobial peptide; HIF-2 $\alpha$, hypoxia inducible factor- $2 \alpha$; HJV, hemojuvelin; TMPRSS6, trans membrane protease serine 6 gene

\section{Introduction}

The total iron content of the human body is $3-4 \mathrm{~g}$ which exists in various forms. The majority is stored as hemoglobin in red blood cells and erythroblasts $(2.5 \mathrm{~g})$. A small amount of iron is also present in the form of proteins i.e., cytochromes, myoglobin, catalase and bound with transferring. ${ }^{1,2}$ The amount of storage iron differs between man and woman although most of them are stored in spleen, liver and bone marrow as hemosiderin and ferritin. This variable iron storage pattern in adult females could be due to menstruation, pregnancies, childbirth, breastfeeding and poor intake.,4 Iron content in the human body is maintained by recycling i.e., from the breakdown of senescent red blood cells by macrophages of the reticuloendothelial system while a minimal amount of iron is daily absorbed and excreted (Figure 1). ${ }^{5}$ The iron metabolism is regulated by interplay of various specific proteins as transferrin, ferritin, iron regulatory protein $1 \& 2$ (IRP1 \& IRP2), Divalent metal transporter 1 (DMT1), Ferroportin, ceruloplasmin, HFE (product of a high-iron gene), Hepcidin, Hemojuvelin, Bone morphogenic protein 6 (BMP6) etc in iron absorption, excretion and recycling. Essentially the circulating form of iron is maintained in the body, bound with transferrin which proffers the soluble form in plasma and averts free radical toxicity. Hepcidin is an acute phase reactant protein primarily synthesized in the hepatocytes of liver. It is also known as liver-expressed antimicrobial peptide (LEAP-1) or hepcidin antimicrobial peptide (HAMP). ${ }^{6-9}$ The two isoforms hepcidin-20 and hepcidin-25 play a role in the iron homeostasis. The hepcidin- 25 has a central role in iron homeostasis, while the exact function of hepcidin-20, in serum iron regulation, is not known. ${ }^{10,11}$ At present no standardized assay is ready for use in the clinical practice although the experimental techniques based on enzyme-linked immune sorbent assay and mass spectrometry were tried. ${ }^{12}$ The aim of this essay is to focus on the current shreds of evidence present in the literature on the role of hepcidin and number of other specific related proteins in the regulation of iron homeostasis.

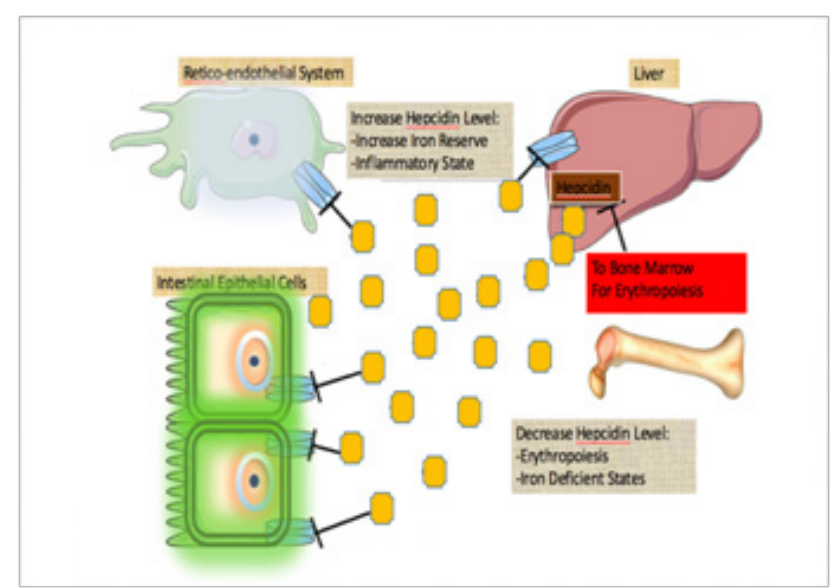

Figure I Homeostasis of iron in reticuloendothelial system and intestinal epitelium.

\section{Discussion}

The advancement in the understanding of iron metabolism has led to the discovery of peptide hormone hepcidin which plays a key role in iron metabolism. ${ }^{6}$ Hepcidin maintains iron homeostasis by interacting with its receptor ferroportin, a trans membrane protein expressed on the surface of macrophages present in the reticuloendothelial system and epithelium lining cells of the intestinal lumen. Ferroportin allows absorbed iron to be transported out into the circulation. The binding of hepcidin with the ferroportin causes its degradation by internalisation thus acts as a negative regulator of iron absorption and recycling. ${ }^{8,13,14}$

\section{Iron recycling}

About 20-25 of iron is recycled every day from the breakdown of senescent red cells in the reticuloendothelial system of human body. Heme released following degradation of hemoglobin of senescent red blood cells by macrophages. This heme is converted by heme oxygenase to biliverdin and carbon monoxide. The resulting 
free iron is released into circulation via ferroportin or stored as ferritin as per requirement (Figure 2)..$^{15-17}$

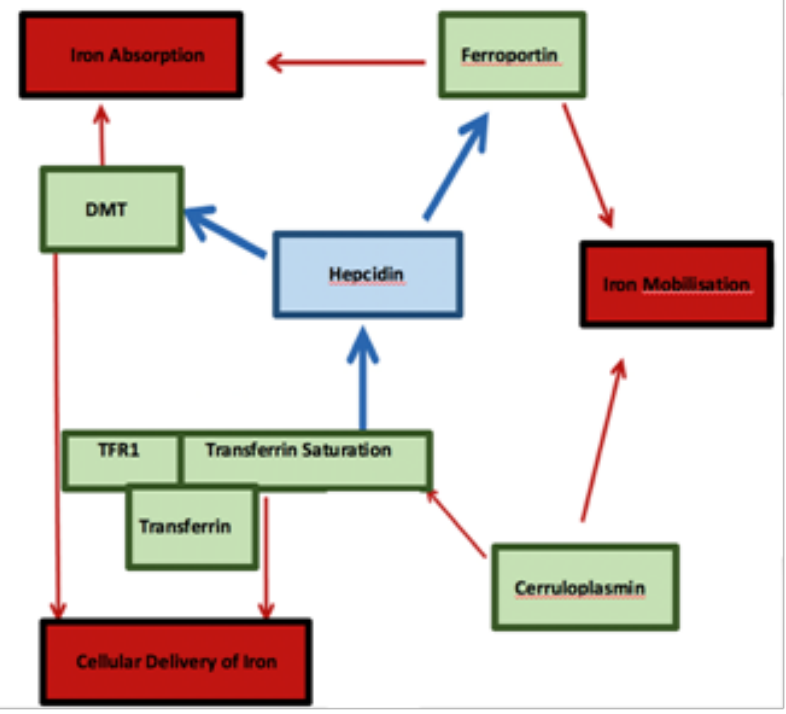

Figure 2 Hepcidin role in mobilization and regulation iron.

\section{Intestinal iron absorption}

Approximately $\sim 1-2 \mathrm{mg}$ of iron is daily added to the human body through this route. ${ }^{18,19}$ A typical daily iron content in the western daily diet is $\approx 15 \mathrm{mg}$ of iron which exist in the form of heme and non-heme iron. ${ }^{20,21}$ Heme is a biologically significant due to its high bioavailability as uptake takes place through its transporter system. The none-heme iron is poorly absorbed due to aqueous and alkaline environment present in the intestinal lumen which promotes conversion of ferrous to ferric form thus limiting its direct absorption. ${ }^{22}$ Ferroportin situated into the basolateral side of enterocytes, loads iron to the transferrin present in circulation (Figure 3). Similar to reticuloendothelial system, hepcidin regulates release and absorption from the intestinal epithelial cells..$^{16,23,24}$

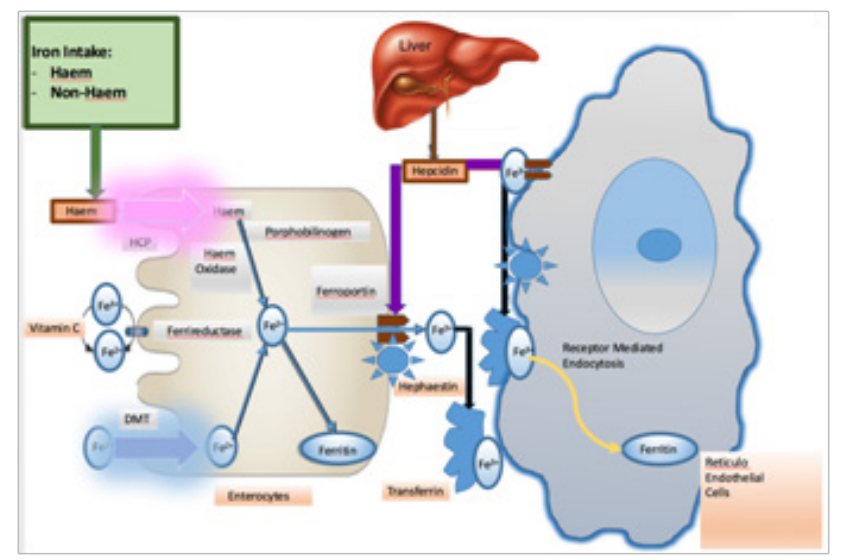

Figure 3 Iron absorption in the gut mucosal cells and transportation into body circulation.

\section{Iron sensing and signaling pathway}

The pathway involving role of hepcidin in iron sensing and signaling is complex and not fully elucidated so far. Meanwhile in light of present knowledge the proposed model has various intercalated pathways which work in coordination with each other. The crucial pathway of hepcidin activation implicates BMP- SMAD pathway. ${ }^{25,26}$ Andriopoulos, et al. ${ }^{27}$ emphasized the role of BMP6 as a ligand for hemojuvelin (HJV) and an endogenous regulator of hepcidin expression and iron metabolism. In cases of iron overload an enriched expression of BMP6 in liver tissues activate its own receptor in the presence of co-receptor $\mathrm{HJV}$, which promotes cooperative interaction and phosphorylation of SMAD1/5/8/4. Further down the chain entire SMAD complex trans locate signal into the nucleus to activate hepcidin transcription. The increased hepcidin level impedes absorption, accumulation and recycling of iron in the body. Nevertheless any dysregulation in component of this sequence leads to various disorders. ${ }^{27-29}$ Nicolas, et al. ${ }^{30}$ Viatte, et al. ${ }^{31}$ proved that increased expression of hepcidin inhibit the iron accumulation in HFE-deficient and beta thalassemia mice models on the other hand Meynard, et al..$^{32}$ reported excessive iron load in a mice model with knocked off the BMP-6 gene..$^{30,32-34}$ Wang, et al. ${ }^{35}$ deciphered the role of hepcidin and SMAD complex in hereditary hemochromatosis. They reported excessive hepatic iron accumulation in the mice model following inactivation of SMAD complex and decreased hepcidin. ${ }^{35}$

Another pathway of hepcidin inactivation involves increased transferrin and HFE-TFR2 complex interaction with BMP-HJVSMAD pathway though its exact way of action in not known. Although study with HFE deficient mice showed that BMP-SMAD pathway is less efficient in the absence of HFE and therapeutic administration of BMP6 is of value in the iron overload. ${ }^{36,37}$ Another pathway of hepcidin activation goes through the Inflammatory cytokines, especially IL6 (and IL1-beta) which induces signal transduction through STAT3. ${ }^{38-42}$ The TMPRSS6 gene and matriptase-2-The most potent negative regulator of hepcidin expression is matriptase-2, which is encoded by the trans membrane protease, serine 6 gene (TMPRSS6). Matriptase-2 exerts its hepcidin regulatory effects by cleaving hemojuvelin, a protein that typically signals to promote hepcidin expression. Along with, that hepcidin expression is also inhibited by the trans membrane protease serine 6 gene (TMPRSS6) encoded protein matriptase-2. Matriptase-2 cleaves hemojuvelin (HJV) protein which is involved in BMP- SMAD pathway. ${ }^{43-45}$

\section{Regulation}

The ferroportin plays a significant role in iron homeostasis and is kept under check by hepcidin. The level of hepcidin in a body is influenced by various physiological and pathological conditions. Hepcidin level is up-regulated following increased serum ferritin, chronic infection, inflammation, C-reactive protein, endotoxin and p53 and is down-regulated in response to iron deficiency, hypoxia, anemia, severe ineffective erythropoiesis and increase in serum erythropoietin. ${ }^{46,47}$ Hypoxia down regulates hepcidin in order to increase iron export via ferroportin, while hypoxia inducible factor-2 (HIF-2 $\alpha$ ) promotes regulatory gene expression that controls iron absorption. ${ }^{48,49}$

\section{Conclusion}

Hepcidin plays a central role in the iron homeostasis metabolism by regulating recycling of iron from senescent red cells, absorption from the gastrointestinal tract and excretion from the body. The better understanding of hepcidin in iron sensing and signaling pathway and its transcription regulators would pave the way for understanding the alteration in iron homeostasis in various physiological and pathological conditions and the development of drugs that could mimic or block 
hepcidin activity. Nevertheless, there is also a necessity to instigate the development of a clinical assay to assess the alterations of hepcidin in various conditions.

\section{Acknowledgements}

None.

\section{Conflict of interest}

Author declares that there is no conflict of interest.

\section{References}

1. Finch CA, Bellotti V, Stray S, et al. Plasma ferritin determination as a diagnostic tool. West J Med. 1986;145(5):657-663.

2. Knovich MA, Storey JA, Coffman LG, et al. Ferritin for the clinician. Blood Rev. 2009;23(3):95-104.

3. Kohgo Y, Ikuta $\mathrm{K}$, Ohtake $\mathrm{T}$, et al. Body iron metabolism and pathophysiology of iron overload. Int J Hematol. 2008;88(1):7-15.

4. Handelman GJ, Levin NW. Iron and anemia in human biology: A review of mechanisms. Heart Fail Rev. 2008;13(4):393-404.

5. De Domenico I, McVey Ward D, Kaplan J. Regulation of iron acquisition and storage: consequences for iron-linked disorders. Nat Rev Mol Cell Biol. 2008;9(1):72-81

6. Ganz T, Nemeth E. Hepcidin and iron homeostasis. Biochim Biophys Acta. 2012;1823(9):1434-1443.

7. Nemeth E. Anti-hepcidin therapy for iron-restricted anemias. Blood. 2013;122(17):2929-2931.

8. Ganz T, Olbina G, Girelli D, et al. Immunoassay for human serum hepcidin. Blood. 2008;112(10):4292-4297.

9. Ramey G, Deschemin JC, Durel B, et al. Hepcidin targets ferroportin for degradation in hepatocytes. Haematologica. 2010;95(3):501-504.

10. Nemeth E, Ganz T. Regulation of iron metabolism by hepcidin. Annu Rev Nutr. 2006;26:323-342.

11. Ganz T, Nemeth E. Hepcidin and disorders of iron metabolism. Annu Rev Med. 2011;62:347-360.

12. Kemna EH, Tjalsma H, Podust VN, et al. Mass spectrometry-based hepcidin measurements in serum and urine: analytical aspects and clinical implications. Clin Chem. 2007;53(4):620-628.

13. Means RT. Hepcidin and anaemia. Blood Rev. 2004;18(4):219-225.

14. Zhao N, Zhang AS, Enns CA. Iron regulation by hepcidin. J Clin Invest. 2013;123(6):2337-2343.

15. Ganz T, Nemeth E. Iron imports. IV. Hepcidin and regulation of body iron metabolism. American journal of physiology. Am J Physiol Gastrointest Liver Physiol. 2006;290(2):G199-G203.

16. Nemeth E, Tuttle MS, Powelson J, et al. Hepcidin regulates cellular iron efflux by binding to ferroportin and inducing its internalization. Science. 2004;306(5704):2090-2093.

17. Nemeth E, Ganz T. The role of hepcidin in iron metabolism. Acta Haematol. 2009;122(2-3):78-86.

18. Layrisse M, Cook JD, Martinez C, et al. Food iron absorption: comparison of vegetable and animal foods. Blood. 1969;33(3):430-443.

19. Hallberg L, Hulthén L. Prediction of dietary iron absorption: An algorithm for calculating absorption and bioavailability of dietary iron. Am J Clin Nutr. 2000;71(5):1147-1160.

20. Hurrell R, Egli I. Iron bioavailability and dietary reference values. Am J Clin Nutr. 2010;91(5):1461S-1467S.
21. Miret S, Simpson RJ, McKie AT. Physiology and molecular biology of dietary iron absorption. Annu Rev Nutr. 2003;23:283-301.

22. Ruz M, Carrasco F, Rojas P, et al. Heme and nonheme-iron absorption and iron status 12 mo after sleeve gastrectomy and Roux-en-Y gastric bypass in morbidly obese women. Am J Clin Nutr. 2012;96(4):810-817.

23. Ganz T. Hepcidin- A regular of intestinal iron absorption and iron recycling by macrophages. Best Best Pract Res Clin Haematol. 2005;18(2):171-182.

24. Reddy MB, Hurrell RF, Cook JD. Meat consumption in a varied diet marginally influences nonheme iron absorption in normal individuals. $J$ Nutr. 2006;136(3):576-581.

25. Goh JB, Wallace DF, Hong W, et al. Endofin, a novel BMP-SMAD regulator of the iron-regulatory hormone, hepcidin. Sci Rep. 2015;5:13986.

26. Darshan D, Anderson GJ. Interacting signals in the control of hepcidin expression. Biometals. 2009;22(1):77-87.

27. Andriopoulos B, Corradini E, Xia Y, et al. BMP6 is a key endogenous regulator of hepcidin expression and iron metabolism. Nat Genet. 2009;41(4):482-487.

28. Camaschella C. BMP6 orchestrates iron metabolism. Nat Genet 2009;41(4):386-388.

29. Babitt JL, Huang FW, Xia Y, et al. Modulation of bone morphogenetic protein signaling in vivo regulates systemic iron balance. J Clin Invest. 2007;117(7):1933-1939.

30. Nicolas G, Viatte L, Lou DQ, et al. Chronic hepcidin induction causes hyposideremia and alters the pattern of cellular iron accumulation in hemochromatotic mice. Blood. 2006;107(7):2952-2958.

31. Viatte L, Vaulont S. Hepcidin, the iron watcher. Biochimie 2009;91(10):1223-1228.

32. Meynard D, Vaja V, Sun CC, et al. Regulation of TMPRSS6 by BMP6 and iron in human cells and mice. Blood. 2011;118(3):747-756.

33. Ahmad KA, Ahmann JR, Migas MC, et al. Decreased liver hepcidin expression in the Hfe knockout mouse. Blood Cells Mol Dis. 2002;29(3):361-366

34. Bridle KR, Frazer DM, Wilkins SJ, et al. Disrupted hepcidin regulation in HFE-associated haemochromatosis and the liver as a regulator of body iron homoeostasis. Lancet. 2003;361(9358):669-673.

35. Wang W, Knovich MA, Coffman LG, et al. Serum ferritin: Past, present and future. Biochim Biophys Acta. 2010;1800(8):760-769.

36. Corradini E, Schmidt PJ, Meynard D, et al. BMP6 treatment compensates for the molecular defect and ameliorates hemochromatosis in $\mathrm{Hfe}$ knockout mice. Gastroenterology. 2010;139(5):1721-1729.

37. Corradini E, Garuti C, Montosi G, et al. Bone morphogenetic protein signaling is impaired in an Hfe knockout mouse model of hemochromatosis. Gastroenterology. 2009;137(4):1489-1497.

38. Wrighting DM, Andrews NC. Interleukin-6 induces hepcidin expression through STAT3. Blood. 2006;108(9):3204-3209.

39. Verga Falzacappa MV, Vujic Spasic M, Kessler R, et al. STAT3 mediates hepatic hepcidin expression and its inflammatory stimulation. Blood. 2007;109(1):353-358.

40. Pietrangelo A, Dierssen U, Valli L, et al. STAT3 Is Required for IL-6gp130-Dependent Activation of Hepcidin In Vivo. Gastroenterology. 2007;132(1):294-300.

41. Huang H, Constante M, Layoun A, et al. Contribution of STAT3 and SMAD4 pathways to the regulation of hepcidin by opposing stimuli. Blood. 2009;113(15):3593-3599. 
42. Armitage AE, Eddowes LA, Gileadi U, Cole S, Spottiswoode N, et al. (2011) Hepcidin regulation by innate immune and infectious stimuli. Blood. 2011;118(15):4129-4139.

43. Heeney MM, Finberg KE. Iron-refractory iron deficiency anemia (IRIDA). Hematol Oncol Clin North Am. 2014;28(4):637-652.

44. Finberg KE, Heeney MM, Campagna DR, et al. Mutations in TMPRSS6 cause iron-refractory iron deficiency anemia (IRIDA). Nat Genet. 2008;40(5):569-571.

45. De Falco L, Totaro F, Nai A, et al. Novel TMPRSS6 mutations associated with Iron-refractory Iron Deficiency Anemia (IRIDA). Hum Mutat. 2010;31(5):E1390-E1405.
46. Donovan A, Lima CA, Pinkus JL, et al. The iron exporter ferroportin/ Slc40a1 is essential for iron homeostasis. Cell Metab. 2005;1(3):191-200.

47. Ward DM, Kaplan J. Ferroportin-mediated iron transport: Expression and regulation. Biochim Biophys Acta. 2012;1823(9):1426-1433.

48. Mastrogiannaki M, Matak P, Delga S, et al. Deletion of HIF-2 $\alpha$ in the enterocytes decreases the severity of tissue iron loading in hepcidin knockout mice. Blood. 2012;119(2):587-590.

49. Mastrogiannaki M, Matak P, Keith B, et al. HIF-2 alpha, but not HIF-1 alpha, promotes iron absorption in mice. $J$ Clin Invest. 2009;119(5):1159-1166. 